\title{
Cervical Pedicle Screw Placement Using Medial Funnel Technique
}

\author{
Jung Hwan Lee', \\ Byung Kwan Choi ${ }^{1}$, \\ In Ho Han", \\ Won Gyu Choi ${ }^{2}$, \\ Kyoung Hyup Nam', \\ Hwan Soo Kim ${ }^{3}$
}

${ }^{1}$ Department of Neurosurgery, Pusan National University Hospital, Busan, ${ }^{2}$ Department of Neurosurgery, Asan Chungmoo Hospital, Asan, ${ }^{3}$ Department of Neurosurgery, Busan Himchan Hospital, Busan, Korea

\section{Corresponding Author: \\ Byung Kwan Choi \\ Department of Neurosurgery, \\ Pusan National University Hospital, Pusan National University School of Medicine, 179 Gudeok-ro, \\ Seo-gu, Busan 49241, Korea}

Tel: +82-51-240-7257

Fax: +82-51-244-8373

E-mail: spine@pusan.ac.kr

Received: June 2, 2017

Revised: August 24, 2017

Accepted: August 27, 2017
Copyright (C) 2017 by The Korean Spinal Neurosurgery Society

This is an open access article distributed under the terms of the Creative Commons Attribution Non-Commercial License (http://creativecommons.org/licenses/bync/4.0/) which permits unrestricted noncommercial use, distribution, and reproduction in any medium, provided the original work is properly cited.

Objective: Cervical pedicle screw (CPS) placement is very challenging due to high risk of neurovascular complications. We devised a new technique (medial funnel technique) to improve the accuracy and feasibility of CPS placement.

Methods: We reviewed 28 consecutive patients undergoing CPS instrumentation using the medial funnel technique. Their mean age was 51.4 years (range, 30-81 years). Preoperative diagnosis included degenerative disease $(n=5)$, trauma $(n=22)$, and infection $(n=1)$. Screw perforations were graded with the following criteria: grade 0 having no perforation, grade 1 having $<25 \%$, grade 2 having $25 \%-50 \%$ and grade 3 having $>50 \%$ of screw diameter. Grades 0 and 1 were considered as correct position. The degree of perforation was determined by 2 junior neurosurgeons and 1 senior neurosurgeon.

Results: A total of 88 CPSs were inserted. The rate of correct placement was $94.3 \%$; grade 0, 54 screws; grade 1, 29 screws; grade 2, 4 screws; and grade 3, 1 screw. No neurovascular complications or failure of instrumentation occurred. In perforated screws (34 screws), lateral perforations were 4 and medial perforations were 30 .

Conclusion: We performed CPS insertion using medial funnel technique and achieved $94.3 \%$ (83 of 88 ) of correct placement. And it can decrease lateral perforation.

Key Words: Cervical vertebrae, Pedicle screws, Bone screws

\section{INTRODUCTION}

Cervical pedicle screw (CPS) instrumentations have biomechanical superiority compared to other cervical posterior fixation techniques, such as posterior wiring, lateral mass screw and facet screw ${ }^{4,5,11,12)}$. However, CPS instrumentations are technically demanding with the risk of neurovascular injury ${ }^{4,8,13,16}$. Since the description of free-hand technique of CPS by Abumi et al. ${ }^{1)}$, many authors have proposed various insertion techniques and reported their accuracies and complication rates ${ }^{4,7,9,13-15,19,20)}$. Among these techniques, the laminoforaminotomy technique has been used widely, because it is a fairly simple procedure. It enables the access to the medial wall of the pedicle. In addition, anatomic orientation can be acquired through probing the superior and inferior borders of the pedicle ${ }^{14,19)}$. However, one surgical challenge is that the surgeon cannot check lateral violation even with fluoroscopy. Thus, relative high rate of lateral perforation may be inevita$b^{19)}$. The funnel technique is a good surgical option because it can prevent lateral violation with direct visualization of the cancellous core of the pedicle ${ }^{7,19)}$. However, some bone loss has arisen during the funnel technique, leading to pull-out strength issue ${ }^{19)}$.

In this study, we devised a new technique of CPS instrumentation called medial funnel technique, to increase the accuracy of CPS placement via direct visualization of screw trajectory while retaining the pull-out strength. The purpose of this study is to describe this medial funnel technique and evaluate its accuracy and validity.

\section{MATERIALS AND METHODS}

\section{Patient Population}

A total of 28 consecutive patients undergoing surgery with CPS instrumentation between January 2010 and December 2015 were included in this study. Their mean age was 51.4 years (range, 30-81 years). There were 19 male and 9 female patients. Preoperative diagnosis included degenerative disease $(n=5)$, traumatic lesion $(n=22)$, and infectious disease $(n=1)$. Our institutional ethics committee approved the protocol for this investigation (Pusan National University Hospital, E-2016044). All investigations were conducted in conformity with ethical principle of research. Informed consent was 
obtained from all participants

\section{Surgical Technique}

Patients were placed in the prone position with the head fixed using Mayfield clamp. A standard midline skin incision was made on posterior neck. Paraspinal muscles were dissected and retracted laterally to expose both facet joints.

The lamina and medial portion of lateral mass were drilled with 2-mm burr under a microscope. After small laminoforaminotomy was made on the upper part of lamina, the ligament flavum at each level was gently dissected free from the inferior aspect of the superior lamina and from the superior aspect of the inferior lamina so that the arch of the medial pedicle cortex could be identified. After drilling the transition zone from lateral mass to the pedicle, the cancellous core of the pedicle was exposed. It was located at the medial part of lateral mass surrounded by the lateral portion of the pedicle (Fig. 1). Thereafter, the screw entry point was created on the superolateral quadrant of the lateral mass under lateral fluoroscopic guidance. Appropriate convergence angle was then confirmed via the exposed cancellous core (Fig. 2). After making an imaginary track from the entry point to the decorticated pedicle cancellous core, a screw was inserted via the decorticated site of medial pedicle cortex under
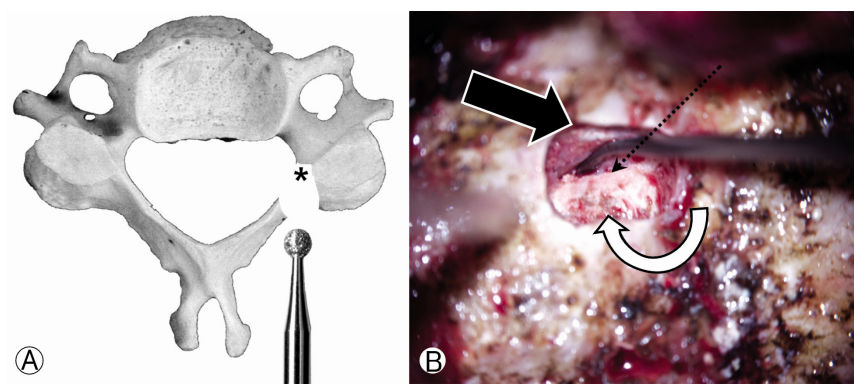

Fig. 1. (A) Schematic illustration of laminoforaminotomy. The cancellous core of pedicle (asterisk) is exposed after drilling on the medial portion of lateral mass and lamina. (B) After making laminoforaminotomy, the dura (full black arrow), medial wall of the pedicle (dotted black arrow) and the cancellous core of the pedicle (curved white arrow) are identified.
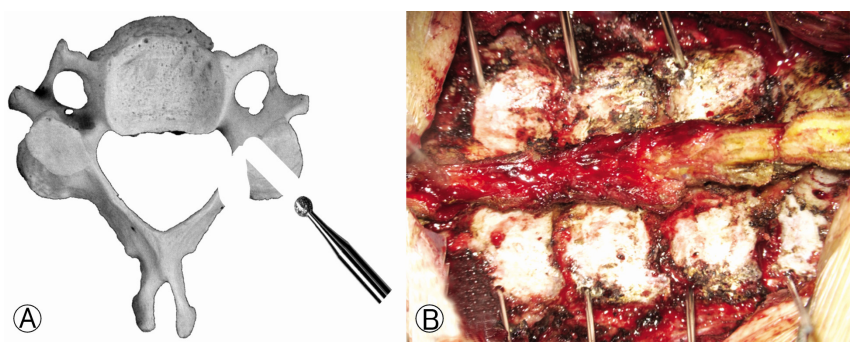

Fig. 2. (A) Schematic illustration of the entry point and trajectory of the pedicle screw. (B) Posterior cervical pedicle entry points on the superolateral quadrant of the lateral mass. direct visualization (Fig. 3). A trajectory was made so that the thread of the screw was exposed through the pedicle cancellous core. If the screw did not pass through the decorticated core of the pedicle, we changed the trajectory. If laminectomy or foraminotomy for neural decompression was necessary, these performed using high speed drill after pedicle screw insertion was completed. Bone fusion was performed using cancellous allograft.

\section{Clinical and Radiographic Analysis}

We reviewed the clinical records and radiographs of all patients. Clinical assessment included neurologic status and pedicle screw-associated complication such as vertebral artery injury and neural injury

Axial computed tomography (CT) scans were obtained with 1-mm slices. Coronal and sagittal reformations were performed preoperatively and postoperatively to assess pedicle screw instrumentation. On preoperative CT scans, the convergence angle and the minimal diameter of the pedicle were measured. On postoperative CT scans, the degree of perforation was classified into four grades. If the CPS located within the pedicle and did not perforated, that was defined as grade 0 perforation. Grade 1 perforation was defined if perforation was less than $25 \%$ of the screw diameter. If perforation was over than $25 \%$ and less than $50 \%$ of the screw diameter, it was classified as grade 2 . Perforation over than 50\% of the screw diameter was defined as grade 3 (Fig. 4). Grades 0 and 1 were regarded as the correct screw position. Grades 2 and 3 were regarded as incorrect screw position. The direction of perforation was classified as medial, lateral, cranial, and caudal.

\section{Interobserver and Intraobserver Error Analysis}

The degree of perforation was confirmed 3 times by 2 junior neurosurgeons. If the degree of perforation differed between 2 junior neurosurgeons, the final decision was made by a senior neurosurgeon. Statistical analysis was performed using IBM SPSS ver. 18.0 (IBM Co., Armonk, NY, USA). The intraobserver and
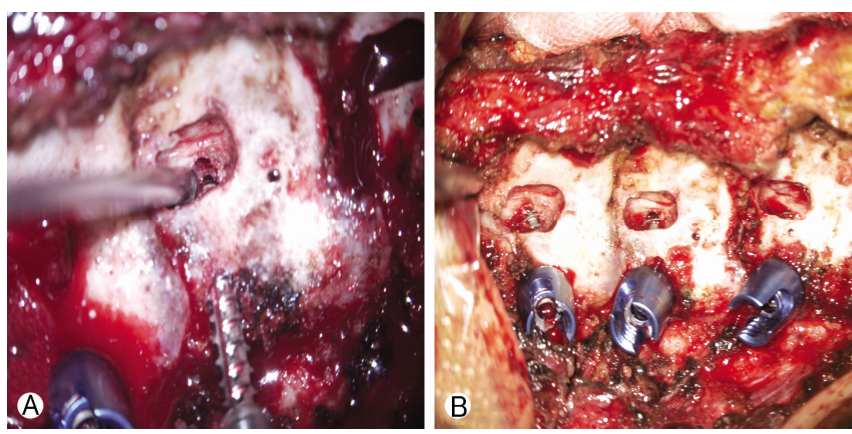

Fig. 3. (A) A pedicle screw was inserted from the entry point to the drilled medial pedicle cortex. (B) After serial cervical pedicle screws were inserted, surgeon could directly see that the screws located in the pedicles. 
interobserver agreement rate and $\kappa$ values were determine the error between 2 observers who graded the pedicle perforation.

\section{RESULTS}

The interobserver agreement rate was $92.7 \%$ for the grade of pedicle perforation (mean $\kappa=0.78$ ). Intraobserver agreement rate was $91.3 \%$ (mean $\kappa=0.71$ ). The intraobserver and interobserver error analyses showed good agreement between the $2 \mathrm{ob}-$ servers. There was no conditions related to vertebral artery injury. Symptom related to nerve root irritation was not observed either after CPS instrumentation. None of the patients showed neurological deterioration after the surgery. There was no serious complication such as surgical site infection.

The average operative time was 174 minutes (range, 111-247 minutes) and the mean blood loss was $234 \mathrm{~mL}$ (range, 100-2,200 $\mathrm{mL})$. A total of 88 CPSs were instrumented, of which 54 CPSs (61.4\%) were classified as grade 0 and $29(33 \%)$ were classified as grade 1 . Four $(4.5 \%)$ were classified as grade 2 and $1(1.1 \%)$ was classified as grade 3 . The mean pedicle diameter was $5.53 \pm$ $1.15 \mathrm{~mm}$, and minimal pedicle diameter was $2.76 \mathrm{~mm}$. Mean
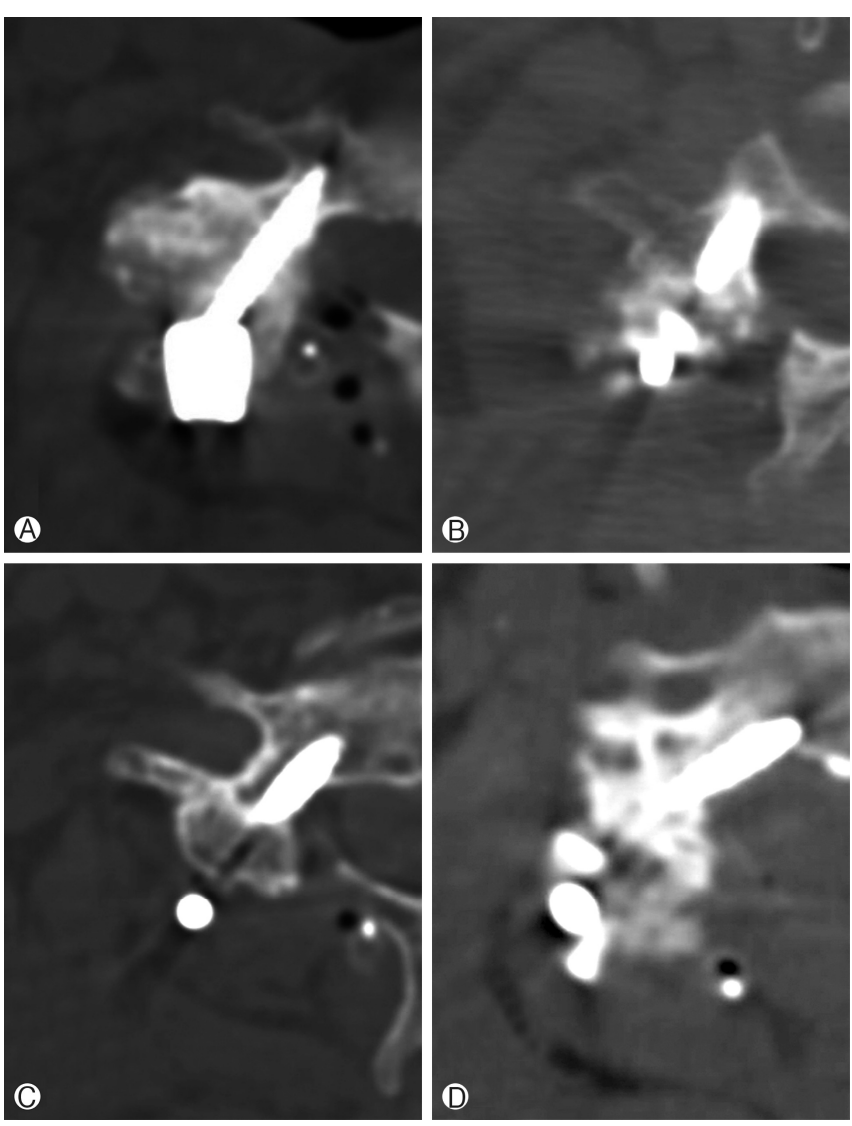

Fig. 4. The grade of pedicle perforation. (A) Grade 0, no pedicle perforation. (B) Grade 1, less than 25\% of screw diameter. (C) Grade 2 , from $25 \%$ to $50 \%$ of screw diameter. (D) Grade 3, over $50 \%$ of screw diameter. pedicle angle was $41.4^{\circ} \pm 11.1^{\circ}$. Ten patients needed laminectomy and foraminotomy for decompression. There was no facetectomy for deformity correction.

These CPSs were divided into correct position (CP) and incorrect position (IP). They were also divided into nonperforation group (NG) and perforation group (PG). Grades 0 and 1 CPSs were allocated into CP, while grades 2 and 3 CPSs were allocated into IP. NG was defined as grade 0 CPSs, while PG was defined as grades 1, 2 and 3. The overall rate of $\mathrm{CP}$ was $94.3 \%$ (83 of 88). IP occurred at C3 in 1 case, C4 in 2 cases, C5 in 1 case, and $\mathrm{C} 6$ in 1 case. IP did not occur at C7 (Table 1). A total of 34 CPSs were included in PG. In PG, 30 CPSs were classified as medial wall perforation while 4 CPSs were classified as lateral wall perforation. Superior or inferior perforation was not identified (Table 2).

\section{DISCUSSION}

Medial funnel technique is basically similar to the funnel technique because they share the same landmarks: medial pedicle cortex with the cancellous core. Direct visualization of the cancellous core of pedicle gives confidence to the surgeon about the pedicle anatomy, and this leads high accuracy of CPS placement. Seo et al. ${ }^{19)}$ have reported that the funnel technique is more accurate than the free-hand or the laminoforaminotomy technique in their cadaveric study. The difference lies in how to expose the cancellous core. In case of the funnel technique, the outer cortex of the lateral mass over the pedicle entrance is removed ${ }^{7}$. In the medial funnel technique, the outer cortex

Table 1. Grade of cervical pedicle screw perforation using the medial funnel technique

\begin{tabular}{lrrrrrc}
\hline \hline Level & C3 & C4 & C5 & C6 & C7 & Total, n (\%) \\
\hline Correct position & & & & & & \\
$\quad$ Grade 0 & 10 & 16 & 13 & 6 & 9 & $54(61.4)$ \\
$\quad$ Grade 1 & 6 & 7 & 5 & 4 & 7 & $29(33.0)$ \\
Incorrect position & & & & & & \\
$\quad$ Grade 2 & 0 & 2 & 1 & 1 & 0 & $4(4.5)$ \\
$\quad$ Grade 3 & 1 & 0 & 0 & 0 & 0 & $1(1.1)$ \\
Total & 17 & 25 & 19 & 11 & 16 & $88(100)$ \\
\hline
\end{tabular}

Table 2. Directions of perforation

\begin{tabular}{lclll}
\hline \hline \multirow{2}{*}{ Direction } & \multicolumn{3}{c}{ Grade of perforation } & \multirow{2}{*}{ Total } \\
\cline { 2 - 4 } & Grade 1 & Grade 2 & Grade 3 & \\
\hline Medial & $25(73.5)$ & $4(11.8)$ & $1(2.9)$ & $30(88.2)$ \\
Lateral & $4(11.8)$ & $0(0)$ & $0(0)$ & $4(11.8)$ \\
Cranial & $0(0)$ & $0(0)$ & $0(0)$ & $0(0)$ \\
Caudal & $0(0)$ & $0(0)$ & $0(0)$ & $0(0)$ \\
Total & $29(98.6)$ & $4(11.8)$ & $1(2.9)$ & $34(100)$ \\
\hline
\end{tabular}

Values are presented as number (\%). 


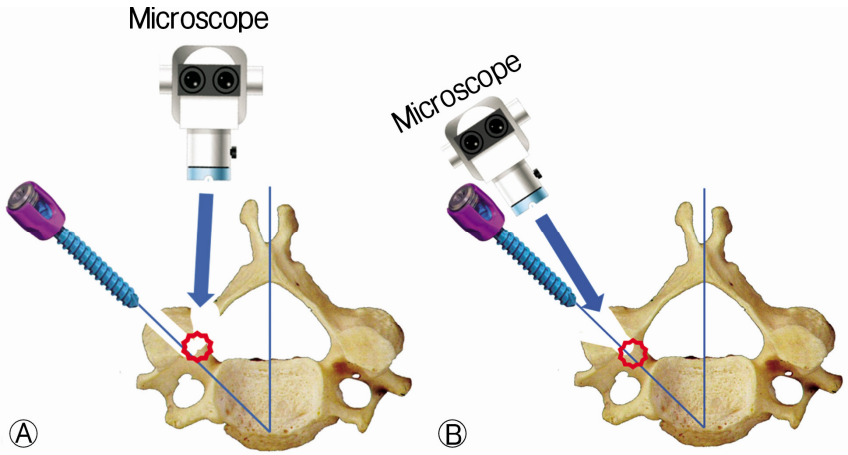

Fig. 5. Comparison between the medial funnel technique and the funnel technique. (A) In the medial funnel technique, the cancellous core of pedicle is exposed by laminoforaminotomy. (B) In the funnel technique, the cancellous core of pedicle is exposed after the removal of lateral mass.

over the pedicle entrance is preserved while the cancellous core is exposed in the middle of screw path by laminoforaminotomy (Fig. 5). In addition, the screw entry point is made minimally on the superolateral quadrant of the lateral mass (Fig. 2). Therefore, the cortical bone near the screw entry point could be preserved maximally, thus maintaining the screw pull-out strength while maintaining high accuracy.

One of the benefit of this technique is that surgeons could see the orientation of pedicle structure without fluoroscopy or a navigation system. Surgeons could draw the imaginary axis of pedicle extended to the lateral mass surface through laminoforaminotomy, and expose the cancellous core of pedicle. This could decrease the necessity of fluoroscopy during screw instrumentation and reduce radiation exposure to surgeons.

The accuracy of CPS placement varied in literature, ranging from $16.8 \%$ to $97 \% \%^{4,714,19)}$. Our series showed a relatively high rate of correct screw position (94.3\%). This result was comparable to CPS placement with navigation system showing accuracy of $93.9 \%$ to $98.8 \% \%^{3,10,18,21)}$. However, the navigation system has some limitation. At first, it is impossible for all institutes to have the navigation system because of the $\operatorname{cost}^{23)}$. Second, there are some clinical conditions in which the navigation system cannot be used such as severe trauma cases requiring intraoperative reduction $^{23)}$. Finally, because the cervical spine is highly mobile, cervical spine alignment can easily change depending on the surgeon's force required for screw insertion ${ }^{22}$. It leads inaccurate synchronization to preoperative images. Therefore, some authors did not use navigation systems in CPS instrumentation ${ }^{22)}$. Additionally, it takes long time to register images during surgery.

The pedicle architecture of the cervical spine usually leads to lateral perforation of CPS during pilot hole preparation, tapping or screw insertion ${ }^{15,17}$. Because the lateral pedicle cortex is commonly thinner than the medial cortex, the use of a blunt pedicle probe is usually directed toward lateral cortex ${ }^{7,15)}$. This also increases the chance of lateral perforation of CPS. Recent multicenter studies have reported that misplaced screws over two-thirds are classified as lateral perforations when the conven- tional free-hand technique is used ${ }^{2,6}$. In laminoforaminotomy technique, the rate of lateral perforation has been reported to be from $72.4 \%$ to $74 \% \%^{4,14)}$. However, the current study indicated that the medial funnel technique had a lower rate of lateral perforations (11.8\%) than the conventional free-hand technique, the laminoforaminotomy technique or the navigation system for CPS placement ${ }^{2,4,19,21)}$.

Our technique has some disadvantages. This technique needs partial laminectomy and process to find pedicle cancellous core. Therefore, additional operative time may be necessary. The risk of postoperative epidural hematoma or cerebrospinal fluid leakage may increase. In addition, intraoperative cord or root injury may happen. Uncontrolled epidural venous bleeding might also disturb the exposure of pedicle.

This study is also limited due to the relatively small number of screws and a heterogeneous group of patients. In addition, our results cannot be compared directly to other studies because the criteria for assessing development and degree of pedicle perforation were different according to each study. In this regard, uniform criterion for pedicle perforations and a larger multicenter study involving multiple surgeons with comparable patient groups are needed.

\section{CONCLUSION}

CPSs instrumentation using medial funnel technique can provide accurate screw positions over $90 \%$ without clinical complications. It can decrease the incidence of lateral perforations. Therefore, this technique could be considered as relatively easy and feasible method for CPS placement.

\section{CONFLICT OF INTEREST}

No potential conflict of interest relevant to this article was reported.

\section{ACKNOWLEDGMENTS}

This work was supported by a 2-year Research Grant of Pusan National University

\section{REFERENCES}

1. Abumi K, Itoh H, Taneichi H, Kaneda K: Transpedicular screw fixation for traumatic lesions of the middle and lower cervical spine: description of the techniques and preliminary report. J Spinal Disord 7:19-28, 1994

2. Hojo Y, Ito M, Suda K, Oda I, Yoshimoto H, Abumi K: A multicenter study on accuracy and complications of freehand placement of cervical pedicle screws under lateral fluoroscopy in different pathological conditions: CT-based evaluation of more than 1,000 screws. Eur Spine J 23:2166-2174, 2014

3. Ito Y, Sugimoto Y, Tomioka M, Hasegawa Y, Nakago K, Yagata Y: Clinical accuracy of 3D fluoroscopy-assisted cervical pedicle screw 
insertion. J Neurosurg Spine 9:450-453, 2008

4. Jo DJ, Seo EM, Kim KT, Kim SM, Lee SH: Cervical pedicle screw insertion using the technique with direct exposure of the pedicle by laminoforaminotomy. J Korean Neurosurg Soc 52:459-465, 2012

5. Jones EL, Heller JG, Silcox DH, Hutton WC: Cervical pedicle screws versus lateral mass screws. Anatomic feasibility and biomechanical comparison. Spine (Phila Pa 1976) 22:977-982, 1997

6. Karaikovic EE, Kunakornsawat S, Daubs MD, Madsen TW, Gaines RW Jr: Surgical anatomy of the cervical pedicles: landmarks for posterior cervical pedicle entrance localization. J Spinal Disord 13: 63-72, 2000

7. Karaikovic EE, Yingsakmongkol W, Gaines RW Jr: Accuracy of cervical pedicle screw placement using the funnel technique. Spine (Phila Pa 1976) 26:2456-2462, 2001

8. Kast E, Mohr K, Richter HP, Börm W: Complications of transpedicular screw fixation in the cervical spine. Eur Spine J 15:327-334, 2006

9. Kim MK, Cho SM, You SH, Kim IB, Kwak DS: Hybrid technique for cervical pedicle screw placement: combination of miniopen surgery and use of a percutaneous cannula system-pilot study. Spine (Phila Pa 1976) 40:1181-1186, 2015

10. Kotani Y, Abumi K, Ito M, Minami A: Improved accuracy of computer-assisted cervical pedicle screw insertion. J Neurosurg 99(3 Suppl):257-263, 2003

11. Kotani Y, Cunningham BW, Abumi K, McAfee PC: Biomechanical analysis of cervical stabilization systems. An assessment of transpedicular screw fixation in the cervical spine. Spine (Phila Pa 1976) 19:2529-2539, 1994

12. Lee CJ, Jeon BC, Chun TS, Kim NK, Park YS: Cervical spine reconstruction using pedicle screw fixation. Korean J Spine 2:232236, 2005

13. Lee SH, Kim KT, Abumi K, Suk KS, Lee JH, Park KJ: Cervical pedicle screw placement using the "key slot technique": the feasibility and learning curve. J Spinal Disord Tech 25:415-421, 2012
14. Ludwig SC, Kramer DL, Balderston RA, Vaccaro AR, Foley KF, Albert TJ: Placement of pedicle screws in the human cadaveric cervical spine: comparative accuracy of three techniques. Spine (Phila Pa 1976) 25:1655-1667, 2000

15. Mahesh B, Upendra B, Mahan RS: The medial cortical pedicle screw--a new technique for cervical pedicle screw placement with partial drilling of medial cortex. Spine J 14:371-380, 2014

16. Neo M, Sakamoto T, Fujibayashi S, Nakamura T: The clinical risk of vertebral artery injury from cervical pedicle screws inserted in degenerative vertebrae. Spine (Phila Pa 1976) 30:2800-2805, 2005

17. Panjabi MM, Shin EK, Chen NC, Wang JL: Internal morphology of human cervical pedicles. Spine (Phila Pa 1976) 25:1197-1205, 2000

18. Richter M, Cakir B, Schmidt R: Cervical pedicle screws: conventional versus computer-assisted placement of cannulated screws. Spine (Phila Pa 1976) 30:2280-2287, 2005

19. Seo YJ, Song GS, Cho WH, Choi BK, Cha SH, Baek SY: Comparison of three different techniques in cervical transpedicular screw insertion. J Korean Neurosurg Soc 39:360-365, 2006

20. Tofuku K, Koga H, Komiya S: Cervical pedicle screw insertion using a gutter entry point at the transitional area between the lateral mass and lamina. Eur Spine J 21:353-358, 2012

21. Uehara M, Takahashi J, Ikegami S, Mukaiyama K, Kuraishi S, Shimizu M, et al: Screw perforation features in 129 consecutive patients performed computer-guided cervical pedicle screw insertion. Eur Spine J 23:2189-2195, 2014

22. Yoshii T, Hirai T, Sakai K, Inose H, Kato T, Okawa A: Cervical pedicle screw placement using intraoperative computed tomography imaging with a mobile scanner gantry. Eur Spine J 25:16901697, 2016

23. Yukawa Y, Kato F, Ito K, Horie Y, Hida T, Nakashima H, et al: Placement and complications of cervical pedicle screws in 144 cervical trauma patients using pedicle axis view techniques by fluoroscope. Eur Spine J 18:1293-1299, 2009 